\title{
LOS VASCOS Y LAS IDENTIDADES REGIONALES EN MÉXICO
}

GENARO ZALPA RAMÍREZ

Departamento de Sociologia/UAA

JAIME OLVEDA (coordinador), Los vascos en el noroccidente de México. Siglos XVI-XVIII, Guadalajara, El Colegio de Jalisco, 1998.

His difícil, para alguien que no es historiador, como yo, apreciar debidamente los méritos propiamente históricos del libro que hoy presentamos. Mis comentarios son, en realidad, las reflexiones que la lectura de la obra suscita en un lector con formación profesional en otra de las ciencias sociales, la sociología.

Uno de los propósitos del libro es avanzar desde la consideración de los conquistadores y colonizadores de México como un bloque homogéneo, los españoles, hacia la consideración más fina de las diferencias de lo que se llama las naciones españolas, entre las que se encuentra la nación Vasca, y lo que estas diferencias significaron para las empresas de conquista y colonización. Entiendo que las investigaciones, las exploraciones que se presentan en el libro que comentamos, serían los primeros pasos que se dirigen hacia ese objetivo. Como lo dice Juan Carlos Reyes Garza: para desenmarañar la madeja de las manifestaciones de las diferentes nacionalidades de los peninsulares y sus descendientes, los criollos, en América, primero debe encontrarse la punta del hilo: cuántos y quiénes fueron los vascos que participaron en la conquista y colonización del noroccidente de México, y qué acciones realizaron.

Aun siendo este libro la búsqueda de la punta del hilo, un lector atento puede descubrir en los autores una convicción compartida: que la participación de los vascos le confirió a la exploración ocasional, aventurera, del noroccidente de Mé- 
xico el carácter de integración sistemática de esos territorios a la colonia. De esta convicción aparentemente compartida surge una primera pregunta: ¿La colonización del noroccidente no se hubiera dado si no hubiera sido por la intervención de los vascos? 0, más simplemente, ¿no se hubiera dado como se dio? ¿Qué características tuvo esta colonización que se pueda relacionar con la cultura propia de los vascos? Los autores, aquí y allá, siembran algunas hipótesis relativas a la cultura vasca y su relación con la empresa de conquista y colonización, como el tesón propio del pueblo vasco, su carácter independiente, su tendencia a actuar como grupo nacional, su catolicismo impregnado de pragmatismo, y otras. Cada una de estas hipótesis hace surgir en el lector otras preguntas.

El tesón, entendido como el gusto por el trabajo y el no arredrarse ante las dificultades ¿puede considerarse como una característica propia de los vascos? ¿No será, más bien, que todos los pueblos gustan considerarse trabajadores y vencedores de las condiciones de su entorno que casi siempre se califican como duras? ¿Fueron los vascos más tesoneros que los gallegos o los andaluces, por ejemplo? Yo creo que solamente un estudio comparativo, como lo señala Jesús Gómez, puede responder estas y otras preguntas relativas a la singularidad de los vascos y lo que esta singularidad habría aportado a la conquista y colonización de América en general, y del noroccidente de México en particular.

Hay, sin embargo, muchos indicadores de la singularidad del pueblo vasco. Se hipotiza, por ejemplo, que es el pueblo más antiguo que se haya asentado en Europa, tal vez el único grupo superviviente de entre sus primeros pobladores. Se reconoce también la singularidad de su lengua $y$, tal parece, hasta de su grupo sanguíneo. Esta singularidad suele relacionarse con su carácter independiente, y en su historia, hasta la actualidad, hay muchas pruebas de este carácter independiente, como lo hace notar Jaime Olveda. En el asunto que nos ocupa, varios de los autores señalan que este carácter independiente hizo a los vascos ignorar límites y prohibiciones de la corona en la empresa de la colonización del noroccidente por lo que, tal vez, se pueda concluir que, sin su participación, la colonización del noroccidente se hubiera dado más tardíamente.

La tendencia a actuar en grupo nacional, regional y hasta familiar, y el tejido de redes sociales de relación y apoyo mutuo que los autores señalan como una característica del pueblo vasco suscita una gran interrogante, derivada de que la lite- 
ratura sociológica reporta esta tendencia como característica de los miembros de todos los grupos nacionales, regionales o familiares cuando emigran (En la misma obra que comentamos, Edgar Gutiérrez habla de las quejas contra la que se llamó "trilogía castellana", derivada de la tendencia de los castellanos a actuar también en grupo y a favorecerse entre sí). Esta interrogante, sin embargo, no le quita importancia al señalamiento de los autores, porque el hecho importante no es que esta sea una característica exclusiva del pueblo vasco, sino que el grupo de origen vasco tuvo una actuación relevante, como grupo, en la conquista y colonización del noroccidente.

Uno de los datos que a mí más me llama la atención es que los colonizadores vascos hayan llamado en su auxilio a una orden religiosa de origen vasco, los jesuitas, para sustituir en la misión evangelizadora del noroccidente a los franciscanos. Espero no enredar más la madeja, cuando de lo que se trata es de encontrar la punta del hilo, si me permito relacionar esta preferencia por los jesuitas, con el catolicismo pragmático de los vascos, y con lo que poco a poco se va volviendo una idea fija: la similitud entre la ética protestante y algunas variantes de la ética católica, entre las que se encontraría, justamente, el catolicismo pragmático de los vascos y el ethos religioso de los jesuitas, a quienes se conoce como la más protestante de la órdenes católicas, precisamente por su pragmatismo y el "metodismo" de su vida religiosa. ¿Será esta una herencia de los vascos al noroocidente de México, particularmente a la red urbana del noroccidente de la que habla Jaime Olveda?

Como primeros pasos en la dirección del propósito general de hacer un análisis más fino de las contribuciones nacionales o regionales a la empresa de la conquista y colonización de América, el libro que comentamos cumple un doble propósito: el de proporcionar materiales que puedan servir de herramientas para otras investigaciones, y sobre todo el de plantear interrogantes pertinentes y significativas que les sirvan como punto de partida: la punta del hilo para desenredar la madeja.

Termino mi comentario con una interrogante referida al propósito general del libro: la aportación específicamente vasca a la conquista y colonización del noroccidente de México y su herencia. Hace unos cuantos años, en las décadas de los sesenta y los setenta, un libro como éste, escrito por mexicanos, hubiera sido difícilmente imaginable. Las ciencias sociales en México, y entre ellas la historia, se encontraban dominadas por el paradigma estructuralista: no había en la sociedad ni en la historia agentes: sólo estructuras. 
Hoy, después de una evolución que se inició en la década de los ochenta, tal parece que las estructuras han sido sustituidas por las acciones de los individuos. Me voy a referir en este punto a un autor francés que tal parece que es, aunque no estoy cierto del dato, coincidentemente vasco: Pierre Bourdieu. En todo caso, este autor hizo una investigación en la región vasca francesa, la región de Bearn (a la que llama su región de origen), cuyos resultados le arrojaron datos aparentemente contradictorios: por un lado descubrió que la institución vasca del mayorazgo (por cierto, ¿otro legado de los vascos a la organización económica de la colonia?) en la transmisión de la herencia de la tierra, que podía considerarse como una imposición estructural, en muchos casos no era obedecida en la práctica, y que los grandes propietarios seguían diversas estrategias para escapar de la imposición estructural. Pero, por otro lado, descubrió también que, en otro orden muy distinto, aunque relacionado, muchos de los herederos de las familias de los grandes propietarios de tierras de Bearn estaban convencidos de elegir libremente la soltería, cuando en realidad era la única opción que les dejaba abierta la imposición estructural en un contexto de grandes flujos de emigración a las ciudades industriales. Necesidad hecha virtud, como dice Bourdieu. ¿Estructura, pues, o agentes? Los dos elementos, responderá más tarde. Pero lo que aquí me interesa enfatizar es que subraya que en el extremo opuesto al concepto de estructura debe encontrarse, en las ciencias sociales, el concepto de agentes, no las acciones de los individuos, pues esta noción, dice, es extraña a las ciencias sociales. Compartiendo en este punto la postura de Bourdieu, termino mi comentario con una pregunta que, creo, no es sino la formulación de otra manera de la pregunta inicial del libro: ¿Los vascos que participaron en la conquista y la colonización del noroccidente, más allá de que participaron como individuos, fueron verdaderos agentes, como vascos, en esa empresa? Yo creo que el trabajo de los autores de este libro es el buen inicio de una respuesta. 